\title{
Meanings attributed by health professionals to the aging process of institutionalized elderly people*
}

\author{
Significados atribuídos por profissionais de saúde ao processo de envelhecimento de idosos \\ institucionalizados
}

Camila Aparecida Pinheiro Landim Almeida ${ }^{1}$, Francisco Nayran de Oliveira Silva ${ }^{1}$, Vânia Angélica de Sousa e Souza $^{1}$, Verlene de Oliveira Santos ${ }^{1}$, Eliana Campêlo Lago ${ }^{1}$, Wanderson Carneiro Moreira ${ }^{2}$

\begin{abstract}
Objective: to analyze the meanings attributed by health professionals to the process of aging of institutionalized elderly. Methods: qualitative study carried out with ten health professionals in two long stay institutions for the elderly. A semistructured interview script was used with questions related to the aging process of institutionalized elderly. The data were analyzed according to the symbol, referent and thought proposed by the Representational Theory of Meaning. Results: the meanings obtained resulted in aspects related to being an elderly; fragile elderly; social exclusion and cultural values (symbol); elements related to the aging process (referent); and the recognition of institutional aspects (thought). Conclusion: the meanings attributed by health professionals to the aging process were related to the fragility of being elderly, in view of social exclusion, cultural aspects and institutionalization. These meanings allow us to reflect on the daily practice of integrality in the care of institutionalized elderly.
\end{abstract}

Descriptors: Aging; Health of Institutionalized Elderly; Health Personnel.

Objetivo: analisar os significados atribuídos por profissionais de saúde ao processo de envelhecimento de idosos institucionalizados. Métodos: estudo qualitativo realizado com dez profissionais de saúde em duas instituições de longa permanência para idosos. Foi utilizado roteiro semiestruturado de entrevista com questões relativas ao processo de envelhecimento de idosos institucionalizados. Os dados foram analisados de acordo com o símbolo, o referente e o pensamento propostos pela Teoria Representacional do Significado. Resultados: os significados obtidos resultaram em aspectos relacionados ao ser idoso; idoso frágil; exclusão social e valores culturais (símbolo); elementos relacionados ao processo de envelhececimento (referente); e o reconhecimento dos aspectos institucionais (pensamento). Conclusão: os significados atribuídos pelos profissionais de saúde ao processo de envelhecimento relacionaram-se à fragilidade de ser idoso, tendo em vista a exclusão social, aspectos culturais e institucionalização. Estes significados permitem refletir sobre a prática cotidiana da integralidade no cuidado aos idosos institucionalizados.

Descritores: Envelhecimento; Saúde do Idoso Institucionalizado; Pessoal de Saúde.

\footnotetext{
*Extracted from the End-of-course "Significado do processo de envelhecimento dos idosos institucionalizados na visão dos profissionais de saúde”, Centro Universitário UNINOVAFAPI, 2015.

${ }^{1}$ Centro Universitário UNINOVAFAPI. Teresina, PI, Brazil.

${ }^{2}$ Universidade do Vale do Paraíba. São José dos Campos, SP, Brazil.
} 


\section{Introduction}

The number of people over the age of 60 has grown rapidly in the last decades, and the prospect is that this number increases by three times in the next 40 years, reaching approximately 65 million by 2050 . Such growth is influenced by morphological, functional and biochemical modifications and interfere in the social adaptive mode and propensity to increased vulnerability to diseases and other harms ${ }^{(1)}$.

Conceptually, aging is a physiological, dynamic and progressive process involving multiple physiological, psychological and social factors that can vary according to the individual. Thus, elderly people need not only individual care, but also the attention of society $^{(2)}$.

However, demographic, social, family and health factors cause the institutionalization of elderly people. It is believed that, among other reasons, the participation of women in the labor market has eliminated the image traditionally given to the care in the home environment, and this causes a problem for the care to be provided to parents or in-laws. There are also changes in family arrangements, loss of functional and cognitive capacity, and need for social contact that reduce the perspective of aging in a family environment ${ }^{(3)}$.

Long stay institutions require professional training to care for institutionalized elderly; ordinances, policies, statutes and/or booklets are not enough without the proper concern for professional qualification $^{(1)}$. Support for training can contribute to the development of health personnel by promoting better practices to address the needs of the institutionalized population $^{(4)}$.

The primary purpose of the National Policy for the Elderly's Health is the recovery, maintenance and promotion of autonomy and independence of the elderly, directing collective and individual health measures for this purpose, in accordance with the principles and guidelines of the Unified Health System. The targets of this policy are all Brazilian citizens aged 60 years and over ${ }^{(5)}$. In this sense, it has been observed that the institutional rights of the elderly are well disseminated, contributing to guide health professionals in the attribution of meanings to the process of aging of the institutionalized elderly.

Therefore, given the relevance of the care provided by health professionals to institutionalized elderly, the present study has its relevance in the possibility of increasing the knowledge about the meaning of the aging process of elderly people residing in long stay institutions. The research question was: what meanings do healthcare professionals attribute to the aging process of institutionalized elderly?

Thus, the objective of this study was to analyze the meanings attributed by health professionals to the aging process of institutionalized elderly.

\section{Methods}

This is a qualitative study that used the Representational Theory of Meaning( ${ }^{(6)}$. The study was carried out in two philanthropic long stay institutions for the elderly in the city of Teresina, Piauí, Brazil, in the months of September and October of 2015.

The participants were health professionals with a higher education who had been working for at least six months in the care of the elderly. Voluntary professionals, professionals on work leave, medical leave or vacations were excluded. The data saturation criterion was adopted to define the number of participants $^{(7)}$, completing the collection phase according to the empirical framework established in the pre-analysis of the research to reach the objective. In this way, ten health professionals with a higher education participated in the study: a dentist, a cardiologist, a speech therapist, a nutritionist, a psychologist, a physiotherapist, two nurses and two social workers.

The data were collected through recorded interviews, which were conducted in a private place, using a semistructured thematic script for the collection of information, guided by the following questions: what meaning do you attribute to the aging of 
the institutionalized elderly? How do you convey the sense of aging to institutionalized seniors? How did your training help you to understand the meaning of aging of the institutionalized elderly? What aspects in your training made it difficult for you to understand the meaning of aging of the institutionalized elderly?

After each interview, the speeches were transcribed verbatim, and the empirical material was read afterwards. Next, relevant ideas were selected to form the units of meaning, which were coded and organized into categories related to the themes. The analysis was based on the three meanings, namely, symbol, referent and thought, proposed by the Representational Theory of Meaning(6).

The results were presented in the form of excerpts from the reports. As a way of preserving anonymity, the letter "P" was used to represent "professional", followed by an Arabic number, indicating the sequence of the interview: (P1), (P2), (P3)... (P10).

The study complied with the formal requirements contained in the national and international regulatory standards for research involving human beings.

\section{Results}

Professionals mentioned symbols related to the emotional state and culture (fragile elderly, social exclusion, cultural values), elements considered relevant to the aging process (referent), as well as the meaning of the implementation of care (thought).

With the meaning of frail elderly the participants mentioned: ...I sense the elderly as sad and emotionally frail, because what they really need, which is the family, they do not have in their daily life (P1). They would like to be with their families; so, we see sad, isolated people who do not interact (P2). There are a number of factors such as age and health (Alzheimer's disease, Parkinson's disease, hypertension, diabetes) that also contribute to premature aging, making family members to seek shelter, as many do not want to care for an elderly person in these situations. But this makes the elderly disappointed, because they would like to be with their family (P9). When the elderly have a family, institutionalized aging is more difficult to accept, because this causes a breakdown of family ties, leading them to express feelings of loneliness and abandonment (P10).

It is observed that the elderly showed fragility before the abandonment of the family, causing diverse psychological damages such as feelings of impotence, low self-esteem and affecting their emotional state. It was also possible to perceive sadness due to the breaking of the family bond. Thus, there is a need for continuous qualification of professionals regarding the approach to the affective demands of institutionalized elderly, through constant promotion of leisure and recreation activities to help in the recovery of autonomy.

With regard to social exclusion, the participants stated: ...The elderly are considered a burden and are generally rejected and excluded (P2). They are subjected to different situations of social exclusion, prejudice, devaluation, maltreatment and abandonment, which affect their health, their dignity and their self-esteem (P4). Although in varying degrees, depending on the situation, they are seen as hurdle in their life; since we receive here sometimes elderly people who were abandoned by the family (P8). I see the elderly being institutionalized as a result of family neglect and abandonment (P9).

These discourses reveal that the elderly feel isolated, excluded and abandoned by the family, with their dignity and self-esteem affected. This emphasizes the importance of social life as an important factor for a better perception of quality of life.

On cultural values, the professionals mentioned: ...Be that you have experiences, knowledge and values (P4). Providing health through the provision of services adapted to the needs, respecting the dignity of the elderly as a human, acting in the symptomatology caused by senilization (P7). For me, it means an opportunity for a dignified and protected aging (P8).

For the elderly to have quality of life, it is necessary that their cultural values, as well as the experiences lived over time, be respected, thus ensuring autonomy, as far as their limitations allow.

In the construction of the referent, the participants mentioned important elements that can be considered as premises in the aging process. ...Aging with quality of life (P3). It means as a valuable experience of life that 
possesses possibilities, limitations, accomplishments and disappointments, as any stage of life (P4). Aging is a challenge, because of the limitations of dependency and, in the institution, this challenge is even greater because they are away from their loved ones (P6). Aging is a natural process of life and may have propitious moments for greater achievements (P7). I try to improve the aging of the elderly through a healthy diet, because through this, they will be able to improve their quality of life and, consequently, increase their life expectancy (P10).

As observed in the speeches, the professionals revealed that some elderly people have difficulty coping with their own aging due to their health condition and the vulnerability in which they are, because there are several factors that contribute to the elderly being institutionalized.

Regarding the meaning in the construction of thought, aspects related to the care institutions were identified: ... I have the impression that the institutions are welcoming and organized (P1). An institution needs to have specific care in several areas and, in dentistry, it is possible to take care of oral health, providing guidance on hygiene, to avoid periodontal diseases, dental caries and other more serious problems (P4). They are welcoming; unfortunately we cannot ignore the reality of the elderly who will be welcomed. He will start a new life, a new coexistence (P8). Institutions seek to create and maintain family ties, thus strengthening a more cozy space; in the case of many, they did not have this experience before (P10).

It is relevant to notice that, no matter how welcoming the long stay institutions may be, as observed in the above reports, the elderly need specific and individualized care. Therefore, the organizational logic of these institutions should not be discarded, but rather complement the specialized care.

\section{Discussion}

The study presents as limitations the restricted field and participants, because as only two long stay institutions were surveyed, and the thoughts and realities of professionals from other institutions and regions of the country cannot be approached. This does not invalidate the results, but rather points to the need for further studies.

According to the perspective of the health professionals investigated, the elderly are fragile. As mentioned in the speeches of the participants, the need for family affection is significant in the life of the elderly. This once again endorses the fact that the family must be present at this stage of life, and provide the necessary support. Corroborating this idea, a study showed that the elderly present specific fragilities in physiological, psychological, and social aspects, resulting from the losses throughout life that make them susceptible to changes in health status, and their problems are characterized by diversity, chronicity and complexity ${ }^{(8)}$.

Institutionalization is motivated by a number of factors, including advanced age, financial issues, increasing need for care, physical and mental problems and lack of space ${ }^{(9)}$. The family is considered the prime social unit in which the elderly are inserted and also the first institution that contributes to their development and socialization, being a reality of arrival, stay and departure of the elderly person ${ }^{(10)}$.

Public health policies determine that it is the duty of the family, the community, the society and the public power to ensure and promote the right to life, health, food, education, culture, sports, leisure, citizenship, freedom, dignity, respect and community coexistence. It is the obligation of the families to keep the elderly in their bosom, in their home, except for cases when they have little of no conditions to provide for their own survival ${ }^{(5)}$. Thus, we emphasize that the recognition of the aging process is fundamental, representing an important family issue, regardless of the joint or separate experience of the event.

Feelings of sadness were present in the reports of health professionals, especially provoked by the rupture of the family bond. It is understood, therefore, that long stay institutions for the elderly still contrast with the ideal of successful aging, because they 
represent solitude, conformity and abandonment. In this perspective, a study arguments that when reexamining life as intimately founded on social relations, which change as one lives longer, being old today contributes to the demystification of prejudices and the change of cultural patterns ${ }^{(11)}$.

It is relevant to highlight the perspective of health professionals about the aging process as complex and dynamic, involving multidimensional elements, in which indivisibility requires attention based on the objective and subjective needs of the elderly person. Thus, long stay institutions, also called nursing homes, are the oldest and most traditional mode of care. By keeping the elderly person out of their family life, this type of housing has the drawback of producing isolation and physical and mental inactivity, thus reducing the quality of life. Institutionalization has become a reality in modern days, serving a greater number of elderly due to demographic, social and health factors $^{(12)}$.

Society has been showing lack of preparation to meet the demands of the aging population, in such a way that this issue has had an escalating impact in political and social spheres, increasing the insecurity of the elderly. The rigidity of long term institutions brings them closer to the so-called total institutions, places of residence and work where large numbers of individuals end up socially isolated and share the formally administered daily routine in their seclusion. These environments hinder interpersonal communication in the community context and erode social and affective life ${ }^{(13)}$.

In this sense, the prejudiced view about aging often results from insufficient information about the subject, generating negative meanings and images, and compromising the experience and interaction between people. These meanings comprise stereotypes that may or may not lead to the exclusion or valuation of the elderly in the community ${ }^{(14)}$.
Quality of life is understood as the individuals' perception of their position in life, in the context of the culture and value system in which they live, and in relation to their goals, expectations, standards and concerns $^{(15)}$. Based on this definition, it is possible to conclude that the care of institutionalized elderly should be individualized and resolute. Health professionals from the various social and education areas should discuss and advance the knowledge regarding the process of human aging. This may allow for more individualized planning, specific training of health professionals and caregivers of the elderly, with relevant knowledge to the expected skills and competences $^{(16-17)}$.

Aging represents a biopsychosocial and cultural process, and because of this, it generates complex demands and requires differentiated care. Successful aging is not a privilege or luck, but a goal to be achieved by those who plan and work for it, including the knowledge on how to deal with the changes brought about by aging.

In this way, there are distinct conceptions among people; some perceive aging as an empty, worthless period in which uselessness and meaninglessness prevail, while for others, aging may be a period of productivity, growth, personal fulfillment, an opportunity to do what one has not done as a young person because they were busy all the time, raising children and searching for family stability ${ }^{(15)}$.

The quality of life of the elderly, proportionally to the length of their life, is generally ensured if they live in their home. In this sense, every effort must be made to keep them in this environment. The home should be place where one feels important, useful, unique, and where one plays a role. After all, the quality of life can be indicated by the ability of the elderly to independently perform the basic activities of daily life $^{(5,18)}$.

The Brazilian population tends to present an 
increasing number of elderly people, what has caught the interest of researchers. Institutions for the elderly need to provide care and dignity to the elderly in order to enhance their quality of life, as well as stimulate independence and self-care as much as possible ${ }^{(12)}$.

The aging process causes several changes, such as physical, mental and psychosocial limitations, that influence the elderly's decision to go to nursing homes. Changes related to physical aspects result from the wear experienced by the elderly, causing diseases and functional difficulties ${ }^{(11)}$.

Long stay institutions for the elderly are considered organizational social systems designed to play the function of assisting elderly people in situations of social vulnerability, that is, elderly without family ties or conditions to ensure their subsistence and needs for housing, food, health and social coexistence ${ }^{(12)}$.

The abandoned elderly may become an institutionalized by own choice or by decision of third parties. On the one hand, institutionalization is beneficial because it provides shelter, access to medical care, food and housing, or because it reduces the burden on caregivers, on the other hand, it represents a weakening or rupture of family and social ties ${ }^{(14)}$.

The feeling of belonging to a group is what underlies social relationships. Thus, the existence of communities is necessary, since these come from the spaces in which individuals can establish relations of greater proximity, of intimacy, that is, more personal connections. Interpersonal relationships are, therefore, extremely important when dealing with new and stressful situations ${ }^{(18)}$.

Provided that Brazilian public policies are instituted for the elderly population, long term institutions must care for and welcome the elderly in a humanized way, providing them with food, housing, personal hygiene and health. In addition, they should also provide recreational, playful, sporting, manual and social activities, so as to ensure healthy and dignified aging.
Finally, the analysis of the meanings attributed by health professionals to the aging process allows us to reflect on the daily practice of integral care for the elderly living in long stay institutions. This reflection makes it possible to discuss the need for specialized training for health professionals and caregivers, as a support for the planning of permanent education actions and potentiate the expected skills and competences.

\section{Conclusion}

The symbols identified as meanings attributed by health professionals resulted in aspects related to being elderly; fragile elderly; social exclusion and cultural values. The relationship with the aging process was obtained as referent, particularly, aging with quality of life. Concerning the meaning in the construction of thought, aspects related to the care institutions, especially reception and organization, were identified.

The grasping of these meanings revealed the relation symbol - referent - thought, with the possibility of influencing the behaviors and conducts in the care of institutionalized elderly people. By raising this discussion based on the Representational Theory of Meaning, it was possible to observe a better understanding of cognitive and symbolic activities related to the aging process, and also reflect on the practice of integral provision of care for institutionalized elderly.

\section{Collaborations}

Almeida CAPL, Silva FNO, Souza VAS and Santos VO contributed to the conception and design, analysis and interpretation of the data, writing of the article, relevant critical review of the intellectual content and final approval of the version to be published. Lago EC and Moreira WC contributed to the relevant critical review of the intellectual content and final approval of the version to be published. 


\section{References}

1. Clegg A, Young J, Iliffe S, Rikkert MO, Rockwood K. Frailty in elderly people. Lancet. 2013; 381(9868):752-62. doi: http://dx.doi. org/10.1016/S0140-6736(12)62167-9

2. Moreira WC, Damasceno CKCS, Vieira SKSF, Campêlo TPT, Campêlo DS, Alencar DC. Assessment of the public policies to cope with violence against the elderly. Rev Enferm UFPE on line [Internet]. 2016 [cited 2017 Aug 13]; 10(4): 1324-31. Available from: http://www.revista. ufpe.br/revistaenfermagem/index.php/revista/ article/viewArticle/9216

3. Santos NO, Beuter M, Girardon-Perlini NMO, Paskulin LMG, Leite MT, Budó MLD. Theperceptions of workers in a long-term care institution for older adults regarding the family. Texto Contexto Enferm. 2014; 23(4):971-8. doi: http://dx.doi. org/10.1590/0104-07072014003170013

4. Alves-Silva JD, Scorsolini-Comin F, Santos MA. Idosos em instituições de longa permanência: desenvolvimento, condições de vida e saúde. Psicol Reflex Crít [Internet]. 2013 [citado 2017 jul. 5]; 26(4):820-30. Disponível em: http://www. scielo.br/pdf/prc/v26n4/23.pdf

5. Damasceno CKCS, Sousa CMM. Análise sobre as políticas públicas de atenção ao idoso no Brasil. R Interd [Internet]. 2016 [citado 2017 mai. 21]; 9(3):185-90. Disponível em: http:// revistainterdisciplinar.uninovafapi.edu.br/index. php/revinter/article/view/985/pdf_356

6. Ogden CK, Richards IA. O significado de significado: um estudo da influência da linguagem sobre o pensamento e sobre a ciência do simbolismo. Rio de Janeiro: Zahar; 1976.

7. Minayo MCS. Amostragem e saturação em pesquisa qualitativa: consensos e controvérsias. Rev Pesq Qual [Internet]. 2017 [citado $2017 \mathrm{fev}$. 13]; 5(7):1-12. Disponível em: http://rpq.revista. sepq.org.br/index.php/rpq/article/view/82

8. Marin MJS, Santana FHS, Moracvick MYAD. The perception of hypertensive elderly patients regarding their health needs. Rev Esc Enferm USP. 2012; 46(1):103-10. doi: http://dx.doi. org/10.1590/S0080-62342012000100014
9. Pinheiro NCG, Holanda VCD, Melo LA, Medeiros $\mathrm{AKB}$, Lima KC. Inequality in the characteristics of the institutionalized elderly in the city of Natal, Brazil. Ciênc Saúde Coletiva. 2016; 21(11):3399405. doi: http://dx.doi.org/10.1590/1413812320152111.19472015

10. Couto AM, Castro EAB, Caldas CP. Experiences to be a family caregiver of dependent elderly in the home environment. Rev Rene. 2016; 17(1):76-85. doi: 10.15253/2175-6783.2016000100011

11. Jerez-Roig J, Oliveira NPD, Lima Filho BF, Bezerra MAF, Matias MGL, Ferreira LM, et al. Depressive Symptoms and Associated Factors in Institutionalized Elderly. Exp Aging Res. 2016; 42(5):479-91. doi: http://dx.doi. org/10.1080/0361073X.2016.1224673

12. Bessa MEP, Silva MJ, Borges CL, Moraes GLA, Freitas CASL. Elderly residents in long-term institutions: the use of spaces in the construction of everyday life. Acta Paul Enferm. 2012; 25(2):177-82. doi: http://dx.doi.org/10.1590/ S0103-21002012000200004

13. Tomicki C, Lini EV, Picoli NRF, Cecchin L, Portella MR. Percepção subjetiva de saúde de idosos residentes em instituições de longa permanência. Rev Bras Ciênc Envelhecimento Hum. 2016; 13(2):219-28. doi: http://dx.doi.org/10.5335/ rbceh.v13i2.5247

14. Oliveira ALB, Dourado MB, Menezes TMO. A percepção dos graduandos de enfermagem sobre envelhecimento. Rev Enferm UERJ [Internet]. 2014 [citado 2017 jul 13]; 22(5):680-5. Disponível em: http://www.facenf.uerj.br/v22n5/v22n5a16.pdf

15. Bettecken K, Bernhard F, Sartor J, Hobert MA, Hofmann M, Gladow T, et al. No relevant association of kinematic gait parameters with health-related quality of life in Parkinson's disease. PLoS One. 2017; 12(5):e0176816. doi: https://doi.org/10.1371/journal.pone.0176816

16. Chaves AS, Santos AM, Alves MTSSB, Salgado Filho $\mathrm{N}$. Association between cognitive decline and the quality of life of hypertensive elderly individuals. Rev Bras Geriatr Gerontol. 2015; 18(3):54556. doi: http://dx.doi.org/10.1590/18099823.2015.14043 
17. Mantovani EP, Lucca SR, Neri AL. Associations between meanings of old age and subjective wellbeing indicated by satisfaction among the elderly. Rev Bras Geriatr Gerontol. 2016; 19(2):20322. doi: http://dx.doi.org/10.1590/180998232016019.150041
18. Almeida CAPL, Oliveira LMM, Franca MJO, Martins AP, Oliveira ADS, Rocha FCV, et al. Risk factors and meaning of violence against the elderly from the perspective of nursing students. Sylwan. 2017 [cited 2017 Apr 8]; 161(7):150-62. Avaliable from: http://sylwan.ibles.org/archive.php?v=161\&i=7 